\title{
The Determinants of Mergers \& Acquisitions in a Resource-Based Industry: What Role for Environmental Sustainability?
}

\author{
ROBERTO LEON-GONZALEZ ${ }^{* \dagger}$ \\ National Graduate Institute for Policy Studies (GRIPS) \\ Rimini Center for Economic Analysis (RCEA) \\ LISE TOLE \\ Rimini Center for Economic Analysis (RCEA)
}

\begin{abstract}
We examine the relationship between environmental stringency and mergers and acquisitions (M\&A) activity in a highly polluting, resource-based industry. Specifically, we seek to determine whether buyers are targeting countries with the same or different levels of environmental stringency than in their own country, i.e. whether pollution havens exist in the global mining industry. Rather than aggregate investment, which has been used by most previous studies, we analyze a dataset of individual investment choices. We model the choice of country and the amount invested jointly as the two variables are likely to be correlated. The choice of country is modeled using a random parameters multinomial Logit model. We use a new data set of the value paid for all completed M\&A in the mining industry worldwide between 1994 and 2006. We find no evidence of pollution havens in this industry. If anything, buyers from countries with high levels of environmental stringency are more likely to invest and make larger investments in countries with a similar level of environmental stringency than in less environmentally stringent countries.
\end{abstract}

Keywords: Environmental stringency, global mining industry, pollution havens, random parameters multinomial logit, sample selection, Bayesian estimation

JEL Classifications: F18, Q56, C11, C33

${ }^{*}$ We thank participants of the Rimini 2011 Bayesian Econometrics Workshop (RCEA) for comments. Lise Tole thanks the British Academy for financial support (Research Grant SG42965) and Roberto LeonGonzalez thanks the Japan Society for the Promotion of Science for financial support under the YoungScientist (B) Grant (\#23730214 and \#26780135).

$\dagger$ Corresponding author: rlg@grips.ac.jp

(c) 2015 Roberto Leon-Gonzalez and Lise Tole. Licenced under the Creative Commons AttributionNoncommercial 3.0 Licence (http: //creativecommons .org/licenses/by-nc/3.0/). Available at http://rofea.org. 


\section{Introduction}

Mergers and acquisitions (M\&A) have expanded rapidly in both developed and developing countries since the early 1990s. Mining and energy industries have played a substantial role in this expansion. Activity during this period was exemplified by Rio Tinto's US $\$ 43 \mathrm{bn}$ purchase of Alcan in the beginning of 2008. This was quickly surpassed by BHP Billiton's failed $\$ 147.4$ billion takeover of Rio Tinto the same year. Had it succeeded it would have been the second largest takeover in corporate history. Since 2009, the global economic recession has seen the value of global M\&A fall substantially, from a record high in 2007 of $\$ 3.16$ trillion, to $\$ 1.49$ trillion in 2010 (Dealogic (2010)).

Economists have identified a number of motives for why firms engage in M\&A activity: to achieve economies of scope and scale, generate new revenues, gain access to new markets, increase managerial specialization and power, engage in cross-selling, and expand geographical distribution. However, Dunning and Lundan (2008) note that for resource industries, in particular, M\&A also provide a means to diversify and acquire new resources. The increasing substitution of M\&A for greenfield investment ${ }^{1}$ in the mining industry since the 1990 s certainly suggests that CEOs have followed this strategy. Since the early 1990s, M\&A in the mining industry have outpaced greenfield investments. M\&A have enabled mining firms to meet the rising demand for metals and minerals in the face of declining supplies, rising exploration costs, and growing political instability in resource rich countries. M\&A have become important vehicles whereby mining companies can diversify, both across countries and commodities ( $\mathrm{PwC}$ 2010).

While such horizontal/vertical models of M\&A activity can provide an explanation for why companies engage in $M \& A$, they do not explain why companies choose to engage in $M \& A$ in one country versus another. One possible explanation may be found in what collectively can be called the "governance infrastructure literature". This rapidly growing body of literature suggests that one strong driver of Foreign Direct Investment (FDI) is the nature and quality of a country's political, economic, and legal policies and institutions. To this list of characteristics, we would also include the quality of a country's environmental regime.

The mining industry, in particular, is heavily polluting. The huge costs involved in setting up even a small operation mean that it is comparatively "non-footloose". Hence governance

\footnotetext{
${ }^{1}$ Greenfield investments are those that start a new venture from scratch in a foreign country.
} 


\section{LEON-GONZALEZ, TOLE Determinants of Mergers \& Acquisitions}

factors, particularly environmental, may figure more prominently in this industry than in others. Indeed, qualitative evidence from CEOs in the mining industry indicates that issues of social and environmental sustainability are beginning to figure prominently in their M\&A decisions (Fonseca et al. 2011; PwC 2007).

Some economists argue that there are economic advantages for companies to locate in countries with less stringent environmental regulations since they can avoid the higher costs of environmental compliance they face at home. This thinking is embodied in the pollution haven hypothesis (e.g. see Fullerton (2006)). In contrast, others argue that environmental factors play no role in investment decisions, i.e. there are no pollution havens. According to this literature, the stringency of a country's environmental regulations does not matter. Firms will adopt similar or even higher standards elsewhere, for reasons such as cost-efficiency and costeffectiveness, "inoculation" against future environmental disasters, avoidance of unnecessary legal costs, pressure from shareholders, and the need to cultivate a green public image. It is also not in the best interests of companies to invest in countries with weak environmental standards because the damage to the company's image from simply being in such countries outweighs any economic gains of locating there irrespective of the actual standard of company environmental performance. Such studies jointly comprise what is known as the pollution halo hypothesis literature (e.g. see Eskeland and Harrison (2003); Zarsky et al. (1999)).

Using a hitherto unexamined data set of all completed M\&A worldwide in the mining industry from 1994-2006, this study will seek to shed light on these competing positions. To this end, it uses a multinomial logit model to measure the role of key environmental and other governance infrastructure variables that could affect mining investments (e.g. economic and financial risk and governance) - not just in the countries that are the target of the M\&A but also in the acquiring companies themselves.

Specifically, our study seeks to shed light on two interrelated questions: Is the environmental stringency of an object country a key factor driving M\&A in the mining industry? Second, does the stringency of the environmental regime of the buyer country itself have any significant influence over its choice of object country? Answering these questions will help us to assess the competing claims of the literature: If we find a significant negative association between the acquiring and object country in respect to the stringency of their environmental regimes, then it is reasonable to argue that this is evidence for the claim that firms are indeed moving 
to countries with lower levels of environmental stringency (i.e. pollution havens exist in the mining industry). However, if we find significant positive associations, then this suggests that buyers are driven to seek out other countries due to their similar environmental regime. In the case of non significant associations, differences in environmental regimes do not play any role in their decision to locate there and consequently pollution havens would not exist in the mining industry.

The remainder of the paper is organized as follows. The next section discusses the empirical context of the study. Section 3 provides a review of relevant papers, focusing on the limitations of the M\&A literature that this study attempts to address. Section 4 discusses the data set, econometric methods and empirical results. Section 5 concludes.

\section{An Overview of Mergers \& Acquisitions in the Mining Industry Since 1995}

The time period broadly encompassed by this study is distinguished by three distinct waves of M\&A activity in the global mining industry: The first wave occurred between 1995 and 1998; the second between 1999-2001 and the third started in 2005, ending abruptly with the global financial crisis in 2008. These mergers have taken place at different points in the price cycle: The mid-1990s and 2005 M\&A waves intensified at a price peak for metals and minerals. The second wave occurred during a price trough (Humphreys (2006)). From wave to wave, the total value of mergers and acquisitions in the industry rose steadily, reaching record levels in 2007. The rise in M\&A activity saw a concomitant fall in the total value spent on exploration during these periods. Exploration costs remained well below the total value of M\&A ( $P w C$ (2008)).

Looking at the first two waves in detail, we note that during the early 1980s to the early 2000s, real term prices for metals and minerals declined steadily due to slumping demand and persistent problems of oversupply. Institutional investors viewed the industry as waning and unprofitable. By 2001 the combined value of quoted mining and metal companies had fallen to a mere US\$ 3 billion, $1 \%$ of all global equity investment (Humphreys (2006)). In response to these adverse trends, industry executives used M\&A to consolidate their financial position. M\&A provided a means of reducing overhead costs, capturing economies of scale and scope, and allocating capital more efficiently in difficult financial times. M\&A were also necessary to ensure competitiveness and diversify geographically in an increasingly globalized business world (Humphreys (2006); PwC (2008)).

The third M\&A wave was driven by sharp increases in the demand for metals and minerals, 


\section{LEON-GONZALEZ, TOLE Determinants of Mergers \& Acquisitions}

fuelled largely by the industrial economies of Asia, especially China. Unlike previous waves, this 3rd wave was distinguished by its focus on expansion rather than consolidation. CEOs became increasingly optimistic about the long-term prospects for the industry. M\&A provided them with a means of maximizing production and supply, acquiring new technologies and expertise, diversifying assets, and generating new production synergies (PwC (2005)). Another key driver in M\&A activity during this period was the dwindling number of viable greenfield sites worldwide. This physical scarcity was exacerbated by increasing costs of new project development and growing government demands for a greater share of profits in the form of taxes and royalties. For large, well-resourced companies like Rio Tinto, industry consolidation through M\&A also provided the infrastructure and technical skills for increasingly difficult to access ore bodies (PwC (2008)). As a consequence of these trends, the real value of M\&A activity in this period rose to a historical high of US\$207 billion in 2007.

The global financial crisis brought an end to this third wave in 2008. Although M\&A have always been a feature of the mining industry, the market capitalization of the top 40 mining companies - an indicator of the health of the industry as a whole - declined by $62 \%$ in 2009 (PwC (2009)). For the most part, only those companies - mainly large, cash-rich Chinese firms looking to secure long-term supplies - were in a position to buy. Most companies focused on consolidation rather than expansion. Consequently, the total value of M\&A fell to $\$ 153.4$ billion in 2008 and to a further US \$77.1 billion in 2009.

\section{Literature Review}

\subsection{Relevant Literature: FDI \& Governance Infrastructure Studies}

A voluminous literature exists on the determinants of FDI flows. Recent papers have attempted to systematically analyze non-economic - in particular - governance-related, determinants of FDI flows. Many have found a significant association between FDI flows and the quality of a country's democratic institutions, the corruptibility and efficiency/transparency of its institutions and depth of its political and civil freedoms. Kolstad and Villinger (2008), for example, find that both institutional quality and democratic accountability are more important than general investment risk or political stability in the financial and other service industries measured in their study. Kolstad and Tondel (2002) also find a positive association between democratic accountability and FDI per capita. In their study of 53 developing countries from 1982 to 1995, 
Review of Economic Analysis 7 (2015) 111-134

$\mathrm{Li}$ and Resnick (2002) find that democratic rights are associated with better protection of property rights, which is an important driver in FDI investment. However, increases in democracy may actually reduce FDI flows. Harms and Ursprung (2002) find that political risk indices and the institutional environment do not affect FDI flows per capita.

Globerman and Shapiro (2002) find a positive association between FDI flows and measures of governance infrastructure, such as policies promoting domestic and international competition, the degree of political openness and transparency of legal and regulatory regimes, and the efficient delivery of government services. Most notable for our study, they find no evidence to suggest that FDI is attracted to developing economies with lower environmental conditions (measured in terms of an index of environmental quality). Rather, they find only very weak evidence at most to suggest that the higher the index of environmental sustainability, the lower the capital outflows.

\subsection{Environmental Motivations underlying FDI Flows: Pollution Haven Hypothesis Studies}

Economic theory predicts that firms will weigh a number of factors when making investment location decisions, including the environmental stringency of the object country (Fullerton (2006)). Specifically, the pollution haven hypothesis argues that highly pollution intensive industries will seek out environmentally lax countries, which tend to be also poorer, in order to avoid the higher costs of environmental compliance at home. According to this hypothesis, the growing liberalization of world trade has led to environmental considerations being at the forefront of decisions about where investments should be made.

Empirical studies have found mixed support for the pollution haven hypothesis. Among the studies that focus on FDI outflows from countries other than the USA, evidence for a role for environmental stringency is much weaker than for either comparable plant location or trade/FDI flow studies for the USA. One such study, by Eskeland and Harrison (2003), finds that abatement costs are not significant determinants of the distribution of foreign investment among manufacturing industries within Mexico, Venezuela, Morocco, and Cote d'Ivoire. Foreign ownership appears to be quite significantly associated with lower energy use, the study's proxy for pollution intensity. Similarly, Smarzynska and Wei (2004) find weak support at best for the possibility that environmental laxity may lead to more foreign investment. Mani et al. (1996) find no evidence that plant location decisions are affected by state level of environmental 


\section{LEON-GONZALEZ, TOLE Determinants of Mergers \& Acquisitions}

enforcement in India. Dean et al. (2009) find evidence that environmental regulations have no impact on joint equity projects between partner firms in Hong Kong, Macau and Taiwan and Chinese regions in highly polluting industries. Moreover, ventures originating from the OECD countries were not driven by low environmental levies, regardless of their water pollution intensity. Tole and Koop (2010) find some evidence that the birth of new copper mines is related to higher levels of country environmental stringency. However, other factors such as political stability and low levels of corruption appear to be stronger determinants.

In contrast, Cole \& Elliot (2005) find that the capital requirements of US sectors is a key determinant of FDI flows, as is the level of pollution abatement costs in the US in FDI flows to Brazil and Mexico, indicating a pollution haven effect for these countries. Kellenberg (2009) finds that as much as $8.6 \%$ of the growth in outbound US multinational affiliate value can be explained by a decline in the relative stringency and enforcement of environmental policies. Similarly, Ederington et al. (2005) find that environmental regulations have a significant effect on trade flows from rich to poor countries, and within industries that face high abatement costs, which also happen to be geographically the least mobile.

\subsection{Drawbacks of Existing Studies}

Most existing studies on country environmental determinants of FDI flows use aggregate measures, which include both greenfield and M\&A investments. Very few focus on M\&A alone. This lacuna is all the more surprising given the growing prominence of M\&A in pollution intensive industries and the different motivations underlying such activity in comparison to greenfield investments. Another drawback is that the overwhelming majority of these studies use data on FDI flows aggregated across industries. However, it is obvious that industries differ widely in their structure and operations, not differentiable in aggregate data. At the same time, the motivations for investing in M\&A may be different for heavily polluting industries such as mining. The vast majority of studies focus on service and manufacturing industries; however, these do not face geographical resource restrictions to the same degree as mining nor do they typically require such a large investment. Thus, the kind of institutions, policies and regulations that may determine M\&A need not be the same at different industries. In particular, it is reasonable to assume that environmental stringency will be a more important consideration in heavily polluting industries such as mining.

Moreover, pooling rich, medium-income and very poor countries together may also obscure 
Review of Economic Analysis 7 (2015) 111-134

important differences in the data. For instance, rich countries do tend to have more stringent environmental regimes and quality, but aggregating data may obscure this fundamental difference. Doing so may also obscure possible threshold effects that could "tip the balance" toward investment in a country (e.g. a minimum level of environmental stringency). Moreover, only a few studies examine the characteristics of buyers and object countries to determine whether the buyer's home country may influence M\&A activity. This is especially the case in respect to environmental standards and quality. Only one such study includes an appropriate control measure for environmental regime (e.g. Globerman and Shapiro (2002)), but in the overall context of a systematic analysis of other governance-related determinants of FDI flows.

\section{Empirical Analysis}

\subsection{Data}

Our data set contains information on the value paid and ore characteristics of all completed M\&A in the mining industry worldwide between 1994 and 2006. We combine this with a panel data on buyer country and object country characteristics, measured between 1994 and 2006. In our dataset, there are mines which were bought by more than one buyer. We use the majority investment firm's head office location as the buyer country. In most cases buyers all came from the same country. The data were derived from a variety of publicly available (e.g. World Bank, ISO) and a proprietary dataset produced for the mining industry (RMG (2007)). Table 1 includes a summary of the data with acronyms and measures.

Dependent Variable. We have two equations and therefore two dependent variables. The dependent variable in the mixed logit model is the country where the investor decides to buy a mine. The other dependent variable is the selling price for the mine after adjusting for differences in ore value. We obtain it as the residuals of a regression of the log of the selling price on a set of 60 dummies representing different types of ore. We have 1719 observations, which is the number of all completed M\&A in the mining industry worldwide between 1994 and 2006. The investors came from 54 different countries and mines were bought in 99 different countries.

Independent Variables: a) Environmental: Since our main focus of the analysis is on the role of environmental stringency in M\&A, we include a number of variables designed to capture the level and quality of environmental stringency and compliance. Most multi-country FDI studies use international treaty-based indicators to measure regulatory stringency (e.g. Smarzynska 
Table 1: Description of Variables

\begin{tabular}{|c|c|c|c|}
\hline Variable & Acronym & Measure & Part of: \\
\hline Value of M\&A & VALUE & $\begin{array}{l}\text { US\$ (mill) paid for object mine after } \\
\text { adjusting for differences in ore value }\end{array}$ & $V_{i j t}$ \\
\hline GDP per capita & GDP & $\begin{array}{l}\text { Real GDP per capita } \\
\text { constant US\$, in logs: } \ln (x+0.01)\end{array}$ & $x_{j t}, z_{i t}$ \\
\hline $\begin{array}{l}\text { Political } \\
\text { Stability }\end{array}$ & POLSTAB & $\begin{array}{l}\text { Durability of } \\
\text { political regime, in logs: } \ln (x+0.01)\end{array}$ & $x_{j t}, z_{i t}$ \\
\hline $\begin{array}{l}\text { Regulatory } \\
\text { Quality }\end{array}$ & REG & $\begin{array}{l}\text { Efficacy of government } \\
\text { regulations for business }\end{array}$ & $x_{j t}, z_{i t}$ \\
\hline $\begin{array}{l}\text { Sulphur dioxide } \\
\text { emissons }\end{array}$ & $\mathrm{SO} 2$ & $\begin{array}{l}\text { Total SO2 emissions millons tons per unit } \\
\text { of GDP as proportion of US emissions } \mathrm{P} \\
\text { per unit of GD, in logs: } \ln (\mathrm{x}+0.01)\end{array}$ & $x_{j t}, z_{i t}$ \\
\hline Openness & OPEN & $\begin{array}{l}\text { \% share GDP } \\
\text { in trade, in logs: } \ln (x+0.01)\end{array}$ & $x_{j t}, z_{i t}$ \\
\hline Investment & INV & $\begin{array}{l}\text { Investment } \\
\text { share of GDP, in logs: } \ln (x+0.01)\end{array}$ & $x_{j t}, z_{i t}$ \\
\hline $\begin{array}{l}\text { Environmental } \\
\text { performance }\end{array}$ & ENVP & $\begin{array}{l}\text { Index of environmental } \\
\text { performance, in logs: } \ln (x+0.01)\end{array}$ & $x_{j t}, z_{i t}$ \\
\hline $\begin{array}{l}\text { ISO } 14001 \\
\text { Certification }\end{array}$ & ISO & $\begin{array}{l}\text { Total ISO } 14001 \\
\text { certifications, in logs: } \ln (x+0.01)\end{array}$ & $x_{j t}, z_{i t}$ \\
\hline $\begin{array}{l}\text { Share world } \\
\text { output }\end{array}$ & PROP & $\begin{array}{l}\text { share of world output } \\
\text { mineral/metal of object country mine } \\
\text { in logs: } \ln (x+0.01)\end{array}$ & $x_{j t}$ \\
\hline $\begin{array}{l}\text { Location of } \\
\text { Head Office }\end{array}$ & LOC & $\begin{array}{l}\text { Head office in same } \\
\text { country; } 1=\text { Yes; } 0=\text { No }\end{array}$ & $I_{i j}$ \\
\hline $\begin{array}{l}\text { Common } \\
\text { Language }\end{array}$ & LANG & $\begin{array}{l}\text { Share common language } \\
1=\text { Yes; } 0=\text { No }\end{array}$ & $L_{i j}$ \\
\hline constant term & CONS & A vector of ones & \\
\hline correlation & CORR & $\begin{array}{l}\text { Constructed regressor whose } \\
\text { coefficient is }-\rho_{i} \text { in equation (4). }\end{array}$ & \\
\hline
\end{tabular}


Review of Economic Analysis 7 (2015) 111-134

and Wei (2004)). Given the absence of complete and comparable cross-country data on environmental regulations for any industry, we also use proxy variables for environmental stringency. On the reasonable assumption that the quality of a country's environment reflects in large part the stringency of its regulations and level of compliance, we use three proxy measures that also reflect the state of a country's environmental performance and concern. This is in contrast to the common practice of using proxies measuring intentional goals (e.g. non-binding international agreements (e.g. anti-whaling treaties). The latter are not always directly applicable to a country's environmental stringency or have little relevance to the control of industrial pollution.

One variable measures a pollutant that is of direct importance to the mining industry. This variable, $\mathrm{SO}$, is a measure of each country's sulphur dioxide production per unit of GDP over that of the US. We express national emissions in terms of US emissions in order to counteract any environmental Kuznets curve impacts of growing emissions over time due to falling or rising real GDP or population. Data for SO2 emissions were derived from Stern (2005), which also provides details on its measurement and sources. Real US GDP data used to construct the measure were derived from Heston et al. (2009).

We would argue that $\mathrm{SO} 2$ emissions provide a very good proxy for the stringency of a country's regulations: First, it is an industrial pollutant regulated throughout the world and commonly measured in standard units. Second, as countries grow and become richer, it is one of the first air pollutants subject to regulation. Even the poorest countries have regulations to control SO2 emissions. Steep initial reductions can usually be achieved by regulators in poor countries by forcing firms to make cheap technological investments. Hence to a greater degree than many other pollutants (e.g. CO2 and NOX emissions) high SO2 emissions indicate an environmental regulatory regime is weak and/or compliance is not being monitored properly. Second, $\mathrm{SO} 2$ emissions are of significant importance to the mining industry. It produces substantial amounts of $\mathrm{SO} 2$, and its control imposes large costs on mining firms in terms of compliance with stringent regulation in richer countries. This variable is also one of the very few environmental measures for which there is a comprehensive dataset covering all the countries in our sample and period of study.

Another environmental variable, designated by the acronym ISO, is designed to tap the extent to which industries and businesses in each country are concerned with improving their environmental performance. This variable is a measure of the total number of ISO 14001 certified 


\section{LEON-GONZALEZ, TOLE Determinants of Mergers \& Acquisitions}

companies in a country. It is derived from yearly reports from the ISO (International Organization for Standardization). Although a voluntary and non-governmental standard, the 14001 standard is internationally recognized. Certification in the standard entails that firms adopt an environmental management system (EMS) which is similar in its goals and application. Thus, unlike many mandatory standards, it can be compared meaningfully across countries. The fact that some countries have a large number of certifications suggests a sensitivity to environmental pollution that is lacking in other countries. Not surprisingly, the largest number of certified firms are in the richest countries of the world.

Our other environmental measure is the Environmental Sustainability Index (ENVP), an annually produced composite index that measures 21 different elements of country environmental sustainability such as: natural resource endowments, past and present pollution levels, environmental management efforts and global commons efforts between 1999 and 2005 (by Yale University's Center for Environmental Law and Policy and Columbia University's Center for International Earth Science Information Network (CIESIN 2006)). Measures for years before 1999 are assigned the 1999 value and for 2006 the 2005 value (although the data used to construct the index comes from various years before the year of publication). Since this ideally measures government commitment to sustainability through a range of policies, it provides a good overall proxy for the level of environmental stringency in a country. The higher the value of the index, the greater the level of sustainability.

b) Political, Regulatory \& Legal Institutions. This data comes from a variety of sources and taps different dimensions of the quality of a country's political and legal institutions. The first measures country political stability (POLSTAB). Stability is measured as.durability of a regime, i.e. how long the regime has been in power, based on the number of years since the last national regime transition. While the risks posed by political instability may be lower in democratic regimes (e.g. Busse and Hefeker (2005)), authoritarian regimes may provide higher returns to investors (Oneal (1994)) because they can provide predictability and hard and fast rules for a firm committed to a country over the long-term. Such firms may even seek to lobby authoritarian governments as a risk management strategy, a route not always possible in democratic regimes. Data were derived from the Center for International Development and Conflict Management (CIDCM 2007).

Our second variable, REG, measures the quality of a country's regulations (including envi- 
ronmental). Derived from the World Bank, it measures the ability of governments to formulate and implement policies and regulations that permit and promote private sector development.

c) Economic \& Financial Variables. Unlike manufacturing and other industries, mining is an extractive activity largely carried out in isolated enclaves for the export rather than domestic market. Hence rather than measure domestic market size, as is common in FDI studies, we measure the percentage of each object country's share of world exports of the main metal or mineral in the M\&A (PROP). The data were derived from RMG 2007. Income level of the country is measured in terms of GDP per capita (GDP) in constant 1996 US dollars and were derived from Heston et al. (2009).

In addition, we also include two variables designed to measure the openness of countries to foreign investment and trade: investment share of real GDP (INV) and percentage of GDP in total trade (OPEN). Both variables are from Heston et al. (2009) and are measured in constant 1996 prices. The first variable was obtained by dividing investment share by real GDP plus exports minus imports. The latter variable was measured as exports plus imports divided by real GDP per capita in constant 1996 US prices.

d) Other Variables. The study also controls for two variables common in FDI studies. The first of these proxies cultural closeness of the buyer and object country, measured by a dummy variable where $1=$ common language between countries and $0=$ no common language. Another proximity variable measures M\&A activity in respect to organizational proximity, i.e. the location of object relative to the buyer country's head office: 1 indicates if the M\&A is in the same country as the buyer country's head office and 0 otherwise. ${ }^{2}$

\subsection{Empirical Methods}

We model the choice of country using a random parameter logit model (McFadden and Train 2000). We assume that each of the mines in the dataset was bought by a different investor so that

\footnotetext{
${ }^{2}$ We initially included a corporate tax rate variable comprised from a number of sources, that had missing values for some countries in our sample. Its inclusion/exclusion did not qualitatively make any difference to the results obtained. Similarly, a mining risk variable data measuring financial risk for the industry was only available for two periods of our study, and we did not include it because its interpretation was difficult as it included many types of risks.

Another variable, often found in gravity models of location/FDI studies, is distance, usually from the FDI source capital city to object country capital city. We did not include such a proximity variable in this study due to the fact that it has little meaning for an extractive industry that operates in enclaves often in remote areas.
} 


\section{LEON-GONZALEZ, TOLE Determinants of Mergers \& Acquisitions}

each purchase is statistically independent of the others. Each investor $i$ has to choose among $J_{t}$ alternatives, where $J_{t}$ is the number of countries from which a mine can be bought at period $t$. Let $c_{i}$ be the home country of investor $i$. We model the unobserved profitability of investing in country $j$ for an investor $i$ from country $c_{i}$ in period $t$ as:

$$
p_{i j t}^{*}=B_{i I}^{p} I_{c_{i} j}+B_{i L}^{p} L_{c_{i} j}+x_{j t}^{\prime} B_{i x}^{p}+\varepsilon_{i j t}^{p} \quad i=1, \ldots, N_{t} \quad j=1, \ldots, J_{t} \quad t=1, \ldots, T
$$

where $x_{j t}$ is a vector of country $j$ characteristics at time $t, I_{i j}$ is a dummy taking value 1 if $c_{i}$ equals $j$ (i.e. investing at home), $L_{c_{i} j}$ is a dummy taking value 1 if countries $c_{i}$ and $j$ speak the same language and $\varepsilon_{i j t}^{p}$ is an error term with extreme value distribution. Each investor will choose the country $j$ for which $p_{i j t}^{*}$ is maximum. The set of choices at year $t$ is assumed to be equal to the set of countries where a mine was sold or bought in year $t$. The number of choices at year $t$ is denoted by $J_{t}$. The parameter $N_{t}$ is the number of mines that were sold in year $t$, such that adding up $N_{t}$ over the different years gives the total number of observations: $\sum_{t=1}^{T} N_{t}=1719$. Note that each investor buys one and only one mine, so that we are not modelling the opt-out option. Instead our model aims to explain the choice of country for an investor who has decided to buy a mine. Although the errors $\left(\varepsilon_{i t j}^{p}: j=1, \ldots, J\right)$ are restricted to be independent among them (with distribution type 1 extreme value, see Cameron and Trivedi (2005, p. 505)), the coefficients $\left(B_{i}^{p}=\left(B_{i I}^{p} B_{i L}^{p} B_{i x}^{p \prime}\right)^{\prime}\right)$ are random and vary among investors $\left(B_{i}^{p} \sim N\left(\mu_{p}, \Sigma_{p}\right)\right)$. As noted by McFadden and Train (2000) this introduces correlation among the $p_{i j t}^{*}(j=1, \ldots, J)$ and allows for a general random utility model. Furthermore, this framework allows each investor to have different preferences. This is particularly important in this context as investors might be located in different countries and/or be interested in different types of ore. As explained below, this framework also allows us to study how the preferences of the investor correlate with the characteristics of its own country. This is information is crucial to determine whether the pollution haven hypothesis holds.

Note that the latent variable $p_{i j t}^{*}$ is not observed. Instead we observe the binary indicator $p_{i j t}$, which is equal to one if alternative $j$ was chosen, and 0 otherwise. Thus in the vector $\left(p_{i 1 t}, \ldots, p_{i J_{t} t}\right)$ only one element is equal to one and all the others are zero. We complete the model with an equation for $V_{i j t}$, which is the value at which the mine was bought after adjusting for differences in ore value. To obtain this we use the value at which the mine was sold and 
regress its logarithm on a set of 60 dummy variables representing different types of ore. Then we obtain $\ln \left(V_{i j t}\right)$ as the residuals from such regression. Finally we specify $\ln \left(V_{i j t}\right)$ as a function of country characteristics as follows:

$$
\ln \left(V_{i j t}\right)=B_{0 i}^{V}+B_{i I}^{V} I_{c_{i} j}+B_{i L}^{V} L_{c_{i} j}+x_{j t}^{\prime} B_{i x}^{V}+\varepsilon_{i j t}^{V}
$$

We introduce correlation between $\varepsilon_{i j t}^{p}$ and $\varepsilon_{i j t}^{V}$ by assuming that $\varepsilon_{i j t}^{V}=\rho_{i} \varepsilon_{i j t}^{p}+\widetilde{\varepsilon}_{i j t}^{V}$, where $\left(\widetilde{\varepsilon}_{i j t}^{V}\right.$, $\left.\varepsilon_{i j t}^{p}\right)$ are independent and $\widetilde{\varepsilon}_{i j t}^{V} \sim N\left(0, \sigma^{2}\right)$. We assume in addition that $\operatorname{cov}\left(\varepsilon_{i j t}^{p}, \varepsilon_{i k t}^{V}\right)=0$ for $j \neq k$. The coefficients $\left(B_{i}^{V}=\left(B_{0 i}^{V} B_{i I}^{V} B_{i L}^{V} B_{i x}^{V \prime} \rho_{i}\right)^{\prime}\right)$ vary among buyers according to $B_{i}^{V} \sim N\left(\mu_{V}, \Sigma_{V}\right)$. Note that $V_{i j t}$ is only observed whenever $p_{i j t}$ equals one.

In addition to models where $\left(\mu_{p}, \mu_{V}\right)$ are constant vectors, we also estimate models where they are linear functions of the characteristics of the buyer $\left(z_{i}\right)$ :

$$
\begin{aligned}
& \mu_{p}=\Pi_{p}\left(\begin{array}{c}
1 \\
\dot{z}_{i}
\end{array}\right) \\
& \mu_{V}=\Pi_{V}\left(\begin{array}{c}
1 \\
\dot{z}_{i}
\end{array}\right)
\end{aligned}
$$

where $z_{i}$ are the average characteristics of buyer $i$ :

$$
z_{i}=\frac{1}{T} \sum_{t=1}^{T} z_{i t}
$$

and $z_{i}$ is the demeaned version of $z_{i}$ :

$$
\dot{z}_{i}=z_{i}-\frac{\Sigma_{i} z_{i}}{\Sigma_{i} 1}
$$

Note that because $\dot{z}_{i}$ is the demeaned version, $\dot{z}_{i}=0$ implies that $z_{i}$ is equal to the average over countries. Thus, the first column of $\Pi_{p}$ (or $\Pi_{V}$ ) represents the effect of covariates $x_{j t}$ on $p_{i j t}^{*}$ (or $\ln \left(V_{i j t}\right)$ ) for a country of average characteristics. The other columns of $\Pi_{p}$ (or $\Pi_{V}$ ) capture how that effect changes with the characteristics of buyer countries.

For computational convenience we follow one of the methods proposed in Dubin and McFadden (1984). First instead of (2) we write: 


$$
\ln \left(V_{i t j}\right)=B_{i 0}^{V}+B_{i I}^{V} I_{c_{i} j}+B_{i L}^{V} L_{c_{i} j}+x_{j t}^{\prime} B_{i x}^{V}+\rho_{i} E\left(\varepsilon_{i j t}^{p} \mid p_{i j t}=1, B_{i}^{p}\right)+\widetilde{\varepsilon}_{i j t}^{V}
$$

As shown by Dubin and McFadden (1984)

$$
E\left(\varepsilon_{i j t}^{p} \mid p_{i j t}=1, B_{i}^{p}\right)=0.57721-\ln \left(\frac{\exp \left(B_{i I}^{p} I_{c_{i} j}+B_{i L} L_{c_{i} j}+x_{j t}^{\prime} B_{i x}^{p}\right)}{\sum_{s=1}^{J_{t}} \exp \left(B_{i I}^{p} I_{c_{i} s}+B_{i L} L_{c_{i} s}+x_{s t}^{\prime} B_{i x}^{p}\right)}\right)
$$

so that (3) can be written as:

$$
\begin{aligned}
\ln \left(V_{i j t}\right)=\quad & B_{i 0}^{V}+B_{i I}^{V} I_{c_{i} j}+B_{i L}^{V} L_{c_{i} j}+x_{j t}^{\prime} B_{i x}^{V} \\
& -\rho_{i} \ln \left(\frac{\exp \left(B_{i I}^{p} I_{c_{i} j}+B_{i L} L_{c_{i} j}+x_{j t}^{\prime} B_{i x}^{p}\right)}{\sum_{s=1}^{J} \exp \left(B_{i I}^{p} I_{c_{i} s}+B_{i L} L_{c_{i} s}+x_{s t}^{\prime} B_{i x}^{p}\right)}\right)+\widetilde{\varepsilon}_{i j t}^{V}
\end{aligned}
$$

The advantage of writing the equations in this way is that $\widetilde{\varepsilon}_{i j t}^{V}$ and $\varepsilon_{i j t}^{p}$ are independent and therefore we can estimate equations (1) and (4) separately. We first run an MCMC algorithm for equation (1) to obtain draws from the posterior of $\left(B_{i l}^{p}, B_{i L}, B_{i x}^{p}\right)$. We then estimate equation (4) by drawing from the conditional distribution of $\left(B_{i 0}^{V}, B_{i I}^{V}, B_{i L}^{V}, B_{i x}^{V}\right)$ given the values of $\left(B_{i I}^{p}, B_{i L}, B_{i x}^{p}\right)$ obtained in the previous estimation. Although the joint estimation of equations (1) and (4) could in theory give slightly more efficient estimates, the procedure that we follow gives valid estimates and credible intervals. In this sense the approach is analogous to the well-known Heckman two step estimation of the sample selection model (Cameron and Trivedi (2005, p. 550)). Details on the prior specification and computational algorithm that we use are given in the appendix.

\subsection{Results}

Table 2 shows the results of estimating equations (1) and (4) when $\left(\mu_{p}, \mu_{V}\right)$ are not allowed to depend on buyers' covariates. We focus only on coefficients whose sign is well determined at the $95 \%$ or $99 \%$ level. By this we mean that the posterior $95 \%$ or $99 \%$ credible interval, respectively, did not contain the value 0 . The factors whose sign is well determined for the location equation (1) are LOC, SO2 at 1\% and GDP, OPEN at 95\%. The coefficient of LOC is positive, indicating that buyer countries are more likely to invest at home, other things being equal. $\mathrm{SO} 2$ is the only environmental variable whose sign is well determined, and the positive sign indicates that buyer countries prefer to invest in countries with more SO2 emissions. However, 
Review of Economic Analysis 7 (2015) 111-134

Table 2: Posterior estimates of $\mu_{p}$ (location eq. (1)) and $\mu_{V}$ (value eq. (4)). Posterior median of each coefficient.

\begin{tabular}{|c|c|c|}
\hline & Location & Value \\
\hline CONS & & 2.82 \\
\hline LOC & 2.56 & -0.1 \\
\hline GDP & 0.17 & 0.05 \\
\hline POLSTAB & 0.01 & 0.02 \\
\hline REG & -0.02 & 0.21 \\
\hline $\mathrm{SO} 2$ & 0.13 & -0.12 \\
\hline OPEN & -0.22 & -0.43 \\
\hline INV & -0.02 & 0.06 \\
\hline ENVP & 0.02 & -0.16 \\
\hline ISO & 0.03 & -0.02 \\
\hline PROP & 0.04 & 0.12 \\
\hline LANG & 0.14 & 0.1 \\
\hline CORR & & -0.12 \\
\hline
\end{tabular}

Notes: The symbols $*^{* * *}, *^{* *}$, and * indicate that the sign of the corresponding coefficient is significant at the $1 \%, 5 \%$ and $10 \%$ level, respectively. 


\section{LEON-GONZALEZ, TOLE Determinants of Mergers \& Acquisitions}

before we can conclude whether this is evidence for the pollution haven hypothesis we need to look at the model that incorporates buyers' covariates. As we will see, the positive sign of $\mathrm{SO} 2$ is explained by the fact that buyer countries with greater levels of $\mathrm{SO} 2$ emissions at home are more likely to invest at home. Hence it is not evidence for the pollution haven hypothesis. With respect to macroeconomic variables, a greater GDP per capita and less openness seem to be characteristics that attract buyer countries. Regarding the value equation, no environmental factors turn out to have a well determined sign. The only two factors that seem to determine the amount of money flowing to object countries are OPEN (with negative sign) and PROP (with positive sign). That is, object countries owning a large percentage of the mineral in question will attract larger investments as will countries whose GDP depends less on trade.

Although Table 2 gives as an overview of the characteristics of countries attracting mining investment, in order to investigate the pollution haven hypothesis we need to look at the correlation between buyer/object characteristics as captured in $\Pi_{V}$ in the value equation (Table 3 ) and $\Pi_{p}$ in the location one (Table 4). Regarding $\Pi_{V}$ we can observe a positive correlation between the political stability of the buyer country and that of the object country, whose sign is well determined at the $95 \%$ level. That is, buyer countries with high political stability value invest more money where the political stability is also high. We also observe a negative correlation, at the $99 \%$ level, between the regulatory quality of the buyer country and the $\mathrm{SO} 2$ emissions of the object country. Thus, buyer countries with better regulatory quality will invest less money in countries where $\mathrm{SO} 2$ is high, other things being constant. The other coefficient whose sign is well determined at the $99 \%$ level in Table 3 is that of the coefficient of PROP in the first column of $\Pi_{V}$. This means that a buyer country with average characteristics invests more money in object countries that own a large percentage of the mineral in question. 
Review of Economic Analysis 7 (2015) 111-134

Table 3: Posterior estimates of $\Pi_{V}$ (value eq. (4)). Posterior median of each coefficient.

\begin{tabular}{|c|ccccccccc|}
\cline { 2 - 9 } \multicolumn{1}{c|}{} & \multicolumn{10}{c|}{ BUYER } \\
\hline OBJECT & CONS & GDP & POLSTAB & REG & SO2 & OPEN & INV & ENVP & SIO \\
\hline CONS & 1.73 & -1.81 & 1.31 & -1.6 & -0.47 & 0.02 & -0.63 & -1.01 & 1.37 \\
LOC & 0.13 & 0.05 & 0.22 & 0.08 & -0.22 & 0.38 & -1.32 & -0.13 & -0.14 \\
GDP & -0.27 & -0.25 & -0.03 & 0.24 & -0.05 & -0.29 & 0.08 & 2.00 & 0 \\
POLSTAB & 0.17 & -0.36 & 0.23 & -0.14 & 0.07 & -0.06 & -0.12 & -0.39 & 0.01 \\
REG & 0.37 & 0.13 & 0.31 & 0.46 & -0.04 & -0.12 & -0.86 & -1.25 & -0.19 \\
SO2 & -0.2 & 0.11 & 0.21 & -0.81 & -0.02 & 0.04 & -0.43 & 0.49 & 0.08 \\
OPEN & -0.04 & 0.62 & 0.44 & -0.46 & 0.14 & 0.35 & -1 & -0.59 & -0.26 \\
INV & 0.93 & 0.25 & -0.06 & -0.57 & 0.2 & 0.53 & 0.2 & -0.78 & -0.15 \\
ENVP & -0.34 & 0.91 & -0.99 & 0.77 & -0.08 & -0.04 & 0.78 & -2.96 & 0.04 \\
ISO & -0.01 & -0.01 & -0.03 & 0.17 & 0 & 0.09 & -0.18 & 0.03 & -0.01 \\
PROP & 0.18 & -0.18 & 0.06 & 0.14 & -0.07 & -0.02 & -0.06 & 0.12 & -0.02 \\
LANG & -0.37 & -0.9 & 0.29 & 0.85 & 0.08 & -0.02 & -0.63 & -1.55 & 0.04 \\
CORR & 0.12 & 0.35 & 0.1 & -0.01 & 0.01 & 0.15 & -0.8 & -0.19 & -0.01 \\
\hline
\end{tabular}

Notes: The symbols $*^{* * *},{ }^{* *}$, and * indicate that the sign of the corresponding coefficient is significant at the $1 \%, 5 \%$ and $10 \%$ level, respectively. The column under CONS represents the effect of object covariates on $\ln \left(V_{i j t}\right)$ for a buyer country of average characteristics. The other columns capture how that effect changes with the characteristics of buyer countries. 
Table 4: Posterior estimates of $\Pi_{p}$ (location eq. (1)). Posterior median of each coefficient.

\begin{tabular}{|c|cccccccccc|}
\cline { 2 - 10 } \multicolumn{1}{c|}{} & \multicolumn{7}{c|}{ BUYER } \\
\hline OBJECT & CONS & GDP & POLSTAB & REG & SO2 & OPEN & INV & ENVP & SIO \\
\hline LOC & 1.3 & 0.96 & -0.07 & -0.53 & 0.64 & 0.17 & -1.73 & 2.38 & 0.09 \\
GDP & 0.08 & 0.22 & -0.04 & 0.09 & 0.07 & -0.04 & -0.07 & -0.29 & -0.01 \\
POLSTAB & 0.05 & 0 & 0.09 & -0.27 & -0.01 & 0.01 & -0.14 & 0.36 & 0 \\
REG & -0.02 & 0.05 & -0.08 & 0.17 & -0.01 & -0.08 & 0.41 & -0.48 & -0.04 \\
SO2 & 0.03 & -0.08 & -0.01 & 0.12 & 0.06 & -0.1 & 0.26 & -0.36 & 0.01 \\
OPEN & -0.1 & -0.11 & 0.06 & 0.04 & -0.06 & 0.21 & 0.03 & -0.27 & -0.03 \\
INV & 0.12 & 0.06 & 0.02 & -0.15 & 0.08 & -0.2 & 0.24 & 0.54 & -0.01 \\
ENVP & 0 & 0 & -0.01 & 0.04 & 0 & -0.08 & 0.08 & 0.27 & -0.02 \\
ISO & 0.01 & -0.13 & -0.01 & 0.07 & -0.01 & 0.03 & 0.03 & 0.04 & 0.04 \\
PROP & 0.03 & -0.02 & 0.02 & -0.07 & 0.01 & -0.06 & -0.07 & 0.13 & 0.01 \\
LANG & 0.72 & 0.38 & -0.07 & -0.02 & 0.32 & -0.3 & -0.95 & 0.5 & 0.05 \\
\hline
\end{tabular}

Notes: The symbols $*^{* * *},{ }^{* *}$, and * indicate that the sign of the corresponding coefficient is significant at the $1 \%, 5 \%$ and $10 \%$ level, respectively. The column under CONS represents the effect of object covariates on $p_{i j t}^{*}$ for a buyer country of average characteristics. The other columns capture how that effect changes with the characteristics of buyer countries. 
Review of Economic Analysis 7 (2015) 111-134

Finally Table 4 shows estimates of $\Pi_{p}$. We find a positive (at the $95 \%$ level) correlation between the political stability of the buyer country and that of the object country: buyer countries with higher political stability tend to choose object countries where political stability is also high, other things being constant. Note that we found this correlation to be positive also in the value equation, so they are not only more likely to choose that location but will also tend to invest more money in it. With respect to environmental variables, although we find mixed evidence for those firms that invest at home, firms that invest abroad are looking for countries with environmental standards similar to their own. We see this in the correlation between the ISO variable of the buyer country and that of object country, which is positive at the $95 \%$ level. On the other hand, the coefficient of LOC in the location equation is positively correlated (at 99\%) with all 3 environmental variables: SO2, ENVP and ISO. Thus buyer countries are more likely to invest at home if home environmental performance is high, according to overall environmental performance (ENVP) and level of voluntary adherence to international environmental standards (ISO), but weak according to $\mathrm{SO} 2$ emissions. Although this mixed finding for domestic investment might be difficult to be interpreted, our main focus is on foreign rather than home investment. And we would argue that the role of environmental factors in M\&A decisions is best captured through our value rather than location equation, because the former pertains directly to the size of M\&A.

To summarize, on the whole, we find no evidence for the pollution haven hypothesis but do find some evidence to suggest that: (1) buyer countries with higher regulatory quality (REG) will invest more in countries with lower SO2 emissions and (2) buyer countries with higher levels of environmental performance (ISO) are more likely to prefer locations with similar levels of environmental performance (ISO).

\section{Conclusions}

This paper has empirically investigated the role that environmental stringency plays in M\&A decisions in the global gold mining industry. Using a unique data set on all completed M\&A in the mining industry between 1994 and 2006, this paper attempted to shed light on the question of whether pollution havens exist in this highly polluting industry. According to the pollution haven literature, buyer firms will more likely try to avoid regulatory liabilities of highly stringent environmental regimes by undertaking M\&A in less environmentally stringent places. Alternatively, firms will be more likely to invest in countries with the same or higher level of 


\section{LEON-GONZALEZ, TOLE Determinants of Mergers \& Acquisitions}

stringency for a number of reasons (e.g. the desire to ensure cost-effectiveness and efficiency in operations, avoid potential environmental liabilities and damage to one's corporate image, and comply with shareholder demands). Our empirical results suggest that the latter position may better describe M\&A in the global mining industry: Firms do not seem to be attracted to countries due to their weak environmental standards. If anything, firms in environmentally cleaner countries tend to invest more money in operations in countries that also have cleaner environments (and implicitly, higher levels of environmental stringency).

Thus, countries wishing to attract foreign investment in the mining industry should focus on policies that improve their environmental record. In addition, our analysis found that other governance infrastructure factors, namely a country's attractiveness in terms of its regulatory quality and political stability, are both important factors in buyers' investment decisions. Although not tested in this study, it is reasonable to think that these factors may also play a contributing role in the level of a country's environmental stringency. Given the importance of these and related environmental variables in our study, it is important that countries consider the overall quality of the governance infrastructure when formulating specific FDI policies.

\section{Appendix}

Let $s(p)$ be the dimension of $\Sigma_{p}, s(V)$ the dimension of $\Sigma_{V}$ and let $I W(S, n)$ denote an inverted Wishart distribution with $n$ degrees of freedom (Bauwens et al. 1999, p. 305). We chose the following priors for variance parameters:

$$
\begin{aligned}
\Sigma_{p} & \sim \operatorname{IW}(0.1 I, s(p)+1) \\
\Sigma_{V} & \sim \operatorname{IW}(0.1 I, s(V)+1) \\
\sigma^{2} & \sim \operatorname{IW}(0.1,2)
\end{aligned}
$$

where $I$ is an identity matrix of appropriate dimension. The prior number of degrees of freedom is the minimum to ensure that the prior is proper and the prior mean is finite. In models where $\left(\mu_{p}, \mu_{V}\right)$ do not depend on covariates we assume that a priori $\mu_{p} \sim N(0,10 I)$ and $\mu_{V} \sim N(0,10 I)$. When $\left(\mu_{p}, \mu_{V}\right)$ are functions of covariates we fix priors on $\Pi_{p}$ and $\Pi_{V}$ as $\operatorname{vec}\left(\Pi_{p}\right) \sim N(0,10 I)$ and $\operatorname{vec}\left(\Pi_{V}\right) \sim N(0,10 I)$.

We respect to computational strategy we first estimate the model defined by equation (1) alone (that is, ignoring the value equation). We do this by using an MCMC algorithm (e.g. 
Koop 2003, p.p. 92-99) defined on 3 block of parameters: $\Sigma_{p}, \mu_{p}\left(\right.$ or $\left.\Pi_{p}\right)$ and $\left(B_{1}^{p}, \ldots, B_{N^{b}}^{p}\right)$. The first two blocks can be generated directly from their conditional posteriors, which are inverted Wishart and normal, respectively. For each of the vectors $B_{i}^{p}$ we use a Metropolis-within-Gibbs step. Instead of drawing $B_{i}^{p}$ at once we decompose $B_{i}^{p}$ into the $\log$ of the norm $\left(\ln \left(B_{i}^{p \prime} B_{i}^{p}\right)\right)$ and direction $\left(\left(B_{i}^{p \prime} B_{i}^{p}\right)^{-1 / 2} B_{i}^{p}\right)$ and draw them in turns. The proposal density for each of them is a symmetric random-walk: a normal for the log of the norm and for the direction a matrix angular central Gaussian distribution (Chikuse, 2003, p. 40). Another possible strategy, which we did not follow, is to draw the vector $B_{i}^{p}$ all at once using a student-t or normal random-walk proposal density.

Conditional on $\left(B_{1}^{p}, \ldots, B_{N^{b}}^{p}\right)$ we can draw the parameters of equation (4) in 4 blocks: $\sigma^{2}, \Sigma_{V}$, $\mu_{V}\left(\right.$ or $\left.\Pi_{V}\right)$ and $\left(B_{1}^{V}, \ldots, B_{N^{b}}^{V}\right)$. Each of them can be drawn directly from its conditional posterior density (normal or inverted Wishart). We combined 5 independent runs of 60000 iterations each after a burn-in of 5000 iterations. Each run used different (randomly chosen) starting values and gave qualitatively similar results, indicating convergence.

\section{References}

Bauwens, L., Lubrano, M. and Richard, J.-F., (1999), Bayesian Inference in Dynamic Econometric Models. Oxford: Oxford University Press.

Busse, M., Hefeker, C. (2005), Political Risk, Institutions, and Foreign Direct Investment, European Journal of Political Economy 23, 397-415.

Cameron, A.C. and Trivedi, P.K. (2005), Microeconometrics: Methods and Applications, Cambridge University Press.

Chikuse, Y., 2003, Statistics on Special Manifolds, volume 174 of Lecture Notes in Statistics, Springer-Verlag, New York.

CIDCM (2007) (Center for International Development and Conflict Management), Political Regime Characteristics and Transitions, 1800 - 2004. Polity IV Dataset. Available at: http://www.cidem.umd.edu/polity/.

CIESIN (Center for International Earth Science Information Network and Yale University Centre for Environmental Law and Policy YCELP) (2006), Environmental Performance Index. Available at: http://sedac.ciesin.columbia.edu/es/epi/index. html.

Cole, M. and Elliot, R. (2005), FDI and the Capital Intensity of "Dirty" Sectors: A Missing Piece of the Pollution Haven Puzzle, Review of Development Economics 9, 530-548. 


\section{LEON-GONZALEZ, TOLE Determinants of Mergers \& Acquisitions}

Dean, J., Lovely, M. and Wang, H. (2009), Are Foreign Investors Attracted to Weak Environmental Regulations? Evaluating the Evidence from China, Journal of Development Economics 90, 1-13.

Dubin, J.A. and McFadden, D.L. (1984), An Econometric Analysis of Residential Electric Appliance Holdings and Consumption, Econometrica 52, 345-362.

Dunning, J. and Lundan, S. (2008), Multinational Enterprises and the Global Economy, 2nd edition. Edward Elgar: London, UK.

Ederington, J., Levinson, A. and Minier, J. (2005), Footloose and Pollution Free, Review of Economics and Statistics 87, 92-99.

Eskeland, G. and Harrison, E. (2003), Moving to Greener Pastures? Multinationals and the Pollution Haven Hypothesis, Journal of Development Economics 70, 1-23.

Fonseca, J. Gonzalez, J.J.S., Salman, S. and Treseder, B. (2011), Schulich International Case Competiton 2011: Mining \& Sustainability. Fletcher School of Law and Diplomancy, Tufts University. Available at: http://fletcher.tufts.edu/ /media/Fletcher/Microsites/CEME/pubs/Final\%20Report\%20S chulich\%20Case\%20Comp.pdf

Fullerton, D. (2006), The Economics of Pollution Havens. Cheltenham, UK: Edward Elgar Publishers.

Globerman, S. and Shapiro, D. (2002), Global Foreign Direct Investment Flows: The Role of Governance Infrastructure, World Development 30, 1899-1919.

Harms, P., Ursprung, H.W. (2002), Do Civil and Political Repression Really Boost Foreign Direct Investment? Economic Inquiry 40, 651-663.

Heston, A, Summers R, and Aten B. (2009), Penn World Table Version 6.2. Center for International Comparisons of Production, Income and Prices at the University of Pennsylvania. Available online at: http://www.bized.co.uk/dataserv/penndata/pennhome.html.

Humphreys, D. (2006), Emerging Players in Global Mining. World Bank Extractive Industries and Development Series \#5. World Bank: Washington, D.C.

Kellenberg, D. (2009), An Empirical Investigation of the Pollution Haven Effect with Strategic Environment and Trade Policy, Journal of International Economics 78, 242-255.

Kolstad, I. and Tøndel, L. (2002), Social Development and Foreign Direct Investments in Developing Countries Report 2002, no11, Chr. Michelsen Institute, Development Studies and Human Rights. 
Review of Economic Analysis 7 (2015) 111-134

Kolstad, I. and Villanger, E. (2008), Determinants of Foreign Investment in Services, European Journal of Political Economy 24, 518-533.

Koop, G. (2003), Bayesian Econometrics, Chichester: Wiley.

Li, Q., and Resnick, A. (2003), Reversal of Fortunes: Democratic Institutions and Foreign Direct Investment Inflows to Developing Countries, International Organization 57, 175-211.

Mani, M., Pargal, S., and Huq, M. (1996), Does Environmental Regulation Matter? Determinants of the Location of New Manufacturing Plants in India in 1994, Policy Research Paper No. 1718. World Bank: Washington, D.C..

McFadden, D., and Train, K. (2000), Mixed MNL Models for Discrete Response, Journal of Applied Econometrics 15, 447-470.

Oneal J. (1994), The Affinity of Foreign Investors for Authoritarian Regimes, Political Research Quarterly 47, 565-588.

Pricewaterhouse Coopers (PwC) 2005, 2007, 2008, 2009. Mining Deals. Available at: http://www.PwC.co.uk/eng/publications/global-mining-deals-recovery-set-to-continue2011.html.

RMG (Raw Metals Group) (2007), Raw Materials Data. Stockholm, Sweden: ET Stockholm AB.

Smarzynska B.K. and Wei, S-J. (2004), Pollution Havens and Foreign Direct Investment: Dirty Secret or Popular Myth? Contributions to Economic Analysis Policy 3 (2).

Stern D. (2005), Global Sulfur Emissions from 1850 to 2000, Chemosphere 58, 163-175.

Tole, L. and Koop, G. (2010), Do Environmental Regulations Affect the Location Decisions of Multinational Gold Mining Firms? Journal of Economic Geography 11, 151-177.

Zarsky, L. (1999), Havens, Halos and Spaghetti: Untangling the Evidence About Foreign Direct Investment and the Environment (Background document, OECD Conference on FDI and the Environment). Paris: Organisation for Economic Cooperation and Development. 